\title{
The New Teaching Model Research on Supply Chain Management Course
}

\author{
Hui Jiang ${ }^{1, \text { a }}$, Qingfeng Sun ${ }^{1, b^{*}}$ and Cuijuan Zhu ${ }^{1, \mathrm{c}}$ \\ ${ }^{1}$ College of Automobile \& Architectural Engineering, Beihua University, China

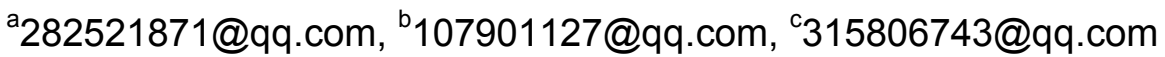

${ }^{*}$ The Corresponding author

Keywords: Supply chain management; Teaching; Primary teaching principle; New model

\begin{abstract}
In the practical teaching course, combined with the supply chain management course the teaching effect is poor, the learning efficiency of students is low, the knowledge is not solid, the ability of solving problem is weak . The primary teaching principle in teaching activities which focusing on the complete task, around "activate the original knowledge", "show demonstrate new knowledge", "try application exercise" and "digest knowledge" four stages. The primary teaching principle to build the five-star teaching mode to improve the teaching effect, improve the learning efficiency. Ultimate realization on training the supply chain management talents who has a complete knowledge structure, strong application ability and innovation ability, and can solve practical tasks.
\end{abstract}

\section{Introduction}

From the educational objectives, the undergraduate education can be divided into innovate application type and research type. In the undergraduate stage, the requirements for logistics talents tend to be innovative and practical, that is, the practical ability is higher than the research talents, and the theoretical ability is higher than the higher vocational talent. This puts forward a high demand for the teaching of supply chain management. For Beihua University, which aims to cultivate innovative students' talents, the supply chain management professional teaching oriented transportation major (logistics direction), the reform measures of establishment of the teaching content system, teaching resources, teaching methods and teaching means will lay a critical foundation in the cultivation of logistics talents, and provide an important reference for the construction of the major orientation course.

In recent years, based on the teaching practice many teachers puts forward the teaching reform direction of the supply chain management[1-3], such as X.Y. Hou proposed that teaching reform of supply chain management based on work process in 2011[4], J.Y. Li put forward the teaching reform of supply chain management based on the cooperation between teachers and students in 2014[5], L.L. Chen proposed the research on teaching method of supply chain management based on experience in 2012[6], H.L. Ge put forward the teaching reform of supply chain management based on demand driven in 2014[7]. Above research, only one kind of teaching idea in" supply chain management" in the teaching of shallow concept, no systematic teaching design and teaching mode, no combined with the actual needs of enterprises to innovative logistics personnel training methods.

\section{The Characteristics of the Supply Chain Management Course}

The supply chain management course which has more content, wide range, high requirements for students' knowledge, strong applicability, practice difficulty, the knowledge source is extensive and updated quickly[8]. The teaching content is theoretical, the teaching methods are simple, the examination method is single, to deliver information depend too much on the teaching media, the students' ability of solving the practical problems is not high. Fig. 1 shows the characteristics of the supply chain management course. 


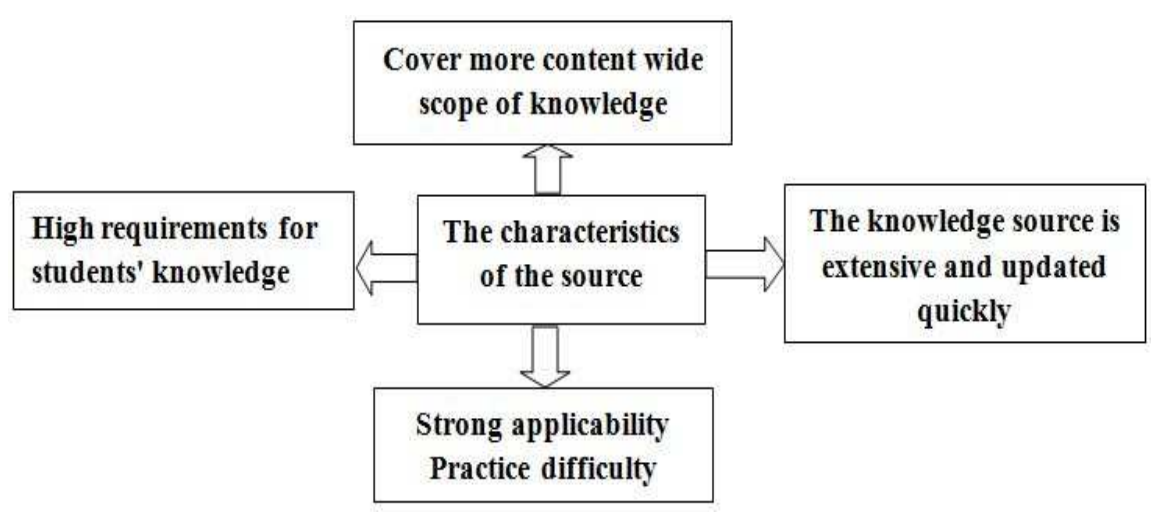

Figure 1. Finite The characteristics of the supply chain management course

\section{The New Teaching Mode of Supply Chain Management}

The Primary Teaching Principle. The primary teaching principle (which is also known as the "five-star" teaching mode) which was designed by the famous contemporary teaching technology and theorists Dr David Merrill in 2001 [9-10].It's focusing on the complete task as the teaching aim which shows that teaching should be repeated in the four phase of the cycle: Activate old knowledge, Learn new knowledge, Try to apply and Achieve mastery through a comprehensive study of the subject, eventually forming "structure-guide-coach-reflection" cycle of teaching. The primary teaching principle not only pay attention to the teaching process, but also pay more attention to the learning process ;Combining teaching theory with teaching design model, to improve the students' learning effectiveness, efficiency and initiative ; First principle of teaching is the new high ground of the teaching process of, which is also the ideal teaching model reform theoretical basis and development tools. Many teachers have used the primary teaching principles in building classes, steam turbine classes, strategic management in the design of teaching.

Construction of a New Mode of Supply Chain Management Teaching Based on the Primary Teaching Principle. Based on the characteristics of the supply chain management course, teaching present situation and existing problems, we can get the key points of the reform that the content of teaching should correspond to the five elements of the primary teaching principle, as been shown in Fig. 1, The primary teaching principle can reconstruct the teaching model with system theory support, and development tools, forming the five-star teaching mode. Fig. 2 presented the new teaching mode based on the primary teaching principle.

Focus on the complete task. The primary teaching principles for the purpose of focuing on the complete task, the learner only by solving the practical problems, who can improve learning. Based on the enterprise requirements the supply chain management course need to adjust the teaching tasks. Therefore, based on the actual decision-making process of enterprise supply management, using a product or a company's actual supply chain for the specific case, refining the complete and complex supply chain management tasks that students need to complete in the course of supply chain management, which including the supply chain strategy, supply chain process improvement, and supply chain performance evaluation, etc. The task of supply chain management is further divided into different units, such as the supply chain process operation into supply chain logistics, information flow, capital operation and business flow operation, etc. According to the logical relation between subtasks from easy to difficult, from simple to complex, from single to diversity order, laying out a complete system of knowledge structure for the students, let students know that after learning, they can complete supply chain management tasks.

Activate the original knowledge. The primary teaching principle show that when the old experience be activated, learning to get promotion. Therefore, according to the cognitive characteristics in the supply chain management course, knowledge skill can be divided into information, ingredients, concepts, procedures, processes, etc. For each kind of knowledge and skills, 
the content structure is set up, such as the main body function, indicate the structure of things, distinguish the type characteristic, design procedures and process rules are given. At the same time, for each kind of knowledge and skills, setting a presentation for its features, such as text, images, formula, multimedia, case, animation and simulation, etc. Therefore, the students can recall the knowledge and skills of enterprise management in the leading courses, practice training, news events and operation practice, and the students can presented in a reasonable content structure and manner.

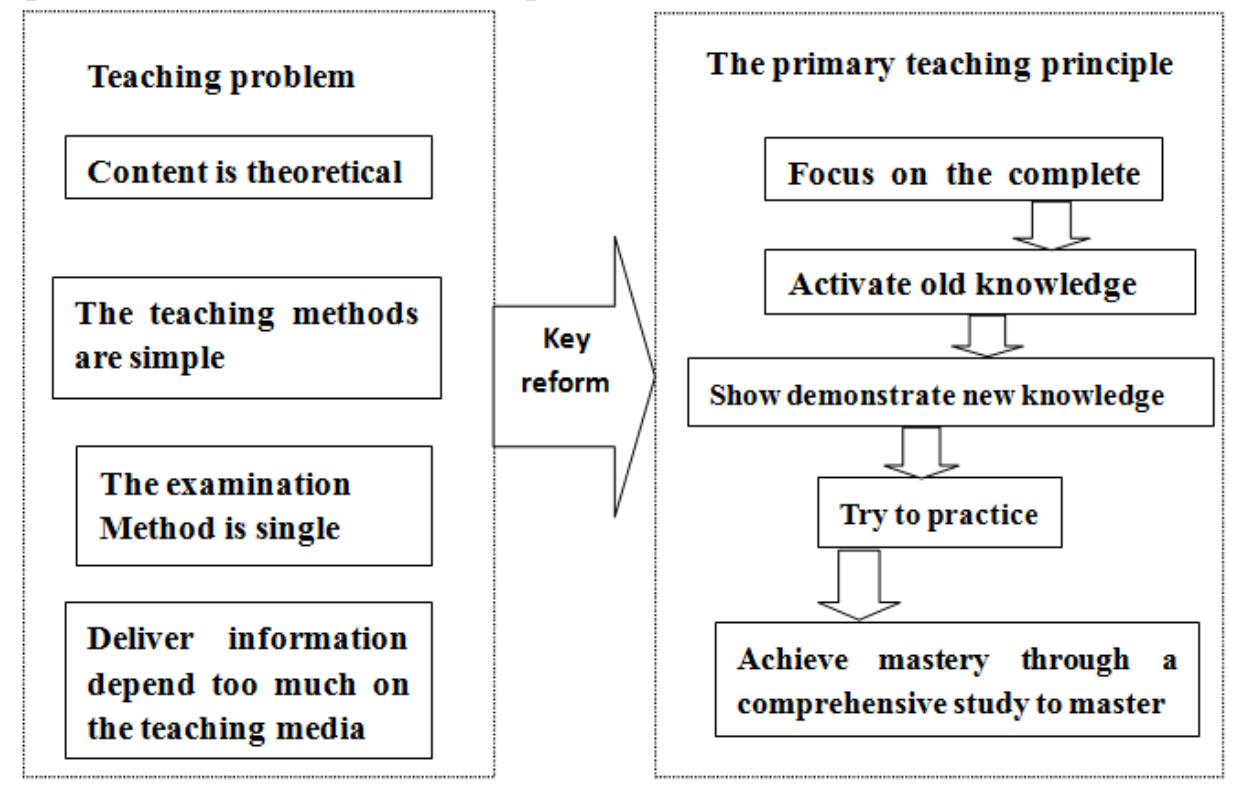

Figure 2. Finite The new teaching mode based on the primary teaching principle

Show demonstrate new knowledge. The primary teaching principle show that each type of skill of knowledge has a matching teaching strategies and teaching methods. According to the type of the knowledge and skills, designing a multidimensional teaching method. Therefore, for five kinds of knowledge and skills such as information, ingredients, concepts, procedures, processes, based on the supply chain management course, to design, games, test, software operation, simulation, case analysis ,video appreciation, on-the-spot investigation, the investigation and analysis of multidimensional teaching method, in order to fully display demonstrates the knowledge and skills, to improve the teaching effect and learning effect.

Try to practice. The primary teaching principle show that learning can be promoted when the learner is asked to use knowledge or skills to solve problems. For the task, design a variety of application situation, stimulate students to use new knowledge. Therefore, design the new tasks such as case analysis, simulation, software operation, the investigation and analysis, the enterprise practice, competition, etc. To form diversified application situation, guide the students' comprehensive application of learned knowledge of supply chain management skills, to check the error and to correct it. At the same time, gradually reduce the guidance in order to enhance the ability of students to solve problems and complete the task. This is not only the process of application knowledge skills, but also the process of assessment and feedback.

Achieve mastery through a comprehensive study to master. The primary teaching principle show that when learners move new knowledge and skills into their daily lives, which can promote learning. According to the characteristics of students, design flexible ways to stimulate students to use new knowledge. Therefore, grouping students according to their performance in the application of knowledge and skills, Through personal reflection, group discussion, group presentations, panel discussions, business practices, competition and other ways to stimulate the students' innovation, practical ability and its application. 


\section{Conclusion}

According to the problem of the supply chain management course, which teaching content is divorced from reality, teaching methods are single, teaching effectiveness and teaching charm just passable, the poor ability of students to solving practical problems. Using the primary teaching principle to construct a new mode of teaching, The formation of five stars teaching mode, in order to improve the teaching effect and promote learning efficiency, cultivate talents who with a complete supply chain management knowledge structure, strong application ability and innovation ability, can solve the actual supply chain management to complex tasks. The new teaching mode need to be improved and optimized. How to choose the most suitable teaching method for the different course content and the task sequence need to weigh the relation between the teaching effect and the difficulty of implementation, and make a reasonable choice.

\section{Acknowledgements}

The education science planning fund project of Jilin Province (No. GH11077)

College teaching project (No. XJYB2016008)

\section{References}

[1] M. David: Journal of distance education, Vol.4 (2007) No.12, p.18.

[2] Z.Z. Du: China logistics and purchasing, Vol. 5 (2010) No.10, p. 74. (In Chinese)

[3] S.W. Ye: Journal of Zhejiang College of Arts and Sciences, Vol. 18 (2014) No.27, p. 334. (In Chinese)

[4] X.Y. Hou: China logistics and purchasing, Vol. 20 (2011) No.5, p. 62. (In Chine se)

[5] J.Y. Li: Contemporary education forum, Vol. 13 (2014) No.22, p. 57. (In Chinese)

[6] L.L. Chen: Wen Hui science and education, Vol.5(2012) No.1,p.73. (In Chinese)

[7] H.L. Ge: Modern trade industry, Vol.8 (2014) No.10,p.24. (In Chinese)

[8] Y. Song, L.Yang: Journal of Suzhou Education Institute, Vol. 15 (2012) No.5,p. 111.

[9] M. D. Merrill: The Primary Teaching Principle (Fujian Education Press, China 2016) , p. 42.

[10] M. D. Merrill: Educational Technology Research and Development, Vol. 50(2002) No. 3, p.49. 